\title{
Estimating the Impact of Covid-19 Outbreak on High-Risk Age Group Population in India
}

\author{
Harjit Pal Singh ${ }^{1} \cdot$ Vikas Khullar $^{1}$ (D) $\cdot$ Monica Sharma ${ }^{2}$
}

Received: 24 April 2020/Revised: 17 June 2020 / Accepted: 21 June 2020/Published online: 1 July 2020

(c) Springer Nature Singapore Pte Ltd. 2020

\begin{abstract}
The new pandemic caused by the severe acute respiratory syndrome coronavirus 2 (SARS-CoV-2), originated at Wuhan, Hubei province, China in December 2019, threatening the world and becomes the public health crisis throughout the globe. Due to changing data and behavior of the current epidemic, appropriate pharmacological techniques to cure are getting delayed day by day. The estimated trends of the global and Indian region for COVID-19 epidemic were predicted for the next 21 days till 05/05/ 2020 on the data recorded till 14/04/2020 in the present work. The main focus of the work was to estimate the trends of COVID19 outbreak on population, especially the high-risk age group of elderly people (with age 50 years and greater) in the Republic of India. It was observed that this identified age-group could be more prone to SARS-CoV-2 virus infection and chances of death in this age group could be more. The high-risk Indian states/regions were also identified throughout the nation and trends for infection, death, and cured cases were predicted for the next 21 days. The outcome of the present work was presented in terms of suggestions that the proper social and medical care for the identified high-risk age group of elderly people of the Indian population should be required to prevent the COVID-19 community transmission. The work also supported the extension in countrywide proper lockdown, mass testing, and also the strict rules to follow social distancing.
\end{abstract}

Keywords COVID-19 · Old age population · Machine Learning · ARIMA · Prediction · Forecasting

\section{Introduction}

In today's scenario, the human race is panicked due to an alarming situation of the recent pandemic of COVID-19. COVID-19 is also depicted as 2019 novel coronavirus (2019-nCoV) or the Severe Acute Respiratory Syndrome Coronavirus 2 (SARS-CoV-2). The initial epicentre of the present pandemic was Wuhan, the capital of Hubei province China in December 2019 [3] but now worldwide humanity is affected by 2019-nCov due to lack of possible cure of this novel virus. The initial transmission mode of this newly

\footnotetext{
$\triangle$ Vikas Khullar

vikas.khullar@gmail.com

Harjit Pal Singh

drhpsingh83@gmail.com

Monica Sharma

er.monicasharma@gmail.com

1 CT Institute of Engineering, Management and Technology, Jalandhar, India

2 GNA University, Phagwara, India
}

discovered 2019-nCov was considered to be cough or sneeze. The World Health Organization (WHO) announced that this virus can enter into the body when a person comes in contact with droplets produced through cough, sneezing or when the person touches some infected any physical area, then touches their eyes, mouth or nose [1]. But, recently WHO published that this COVID-19 virus is airborne and can spread through breathing or even just talking [7]. The initial symptoms of COVID-19 virus infection were found to be cough, sore throat, fatigue, which could lead to fever, diarrhea, and malaise among others. Further, due to humanto-human transmission, the exponential increment in the number of infectious cases was observed [1, 3, 27].

According to WHO till 14/04/2020, from China to the rest of the world in 206 countries, areas or territories, around 1,844,863 cases of coronavirus infections and 117,021 deaths have been reported [6]. In Indian scenario, the observed trends of virus transmission till 24/03/2020, expected the local or initial stage of COVID-19 epidemic. Most of the cases were found to be migrants, overseas visitors, and some others who were in contact with these 
infected persons. To tackle this initial transmission, the countrywide lockdown was called by the Indian Government. The situation seemed to be under control due to lockdown till 24/03/2020, since the total number of confirmed and death cases found to be 511 and 10, respectively, as presented in Table 1. But now till 14/04/2020, India has reported 11,488 cases and further trends are discussed in Table $1[8,11]$. The frightening trends were reported from 04/04/2020, when the number of confirmed cases increased drastically and shoot up to 2650 from 909 as reported on 28/03/2020 and presented in Table 1 . The sudden horrifying increment in cases was occurred due to the religious gathering in New Delhi and its spread throughout the country, which lead to human-to-human transmission of COVID-19 in India. Initially, most of the people, who came in contact with such infected persons, were unaware of the virus symptoms in their bodies. The prime cause of the virus spread was supposed to be fear and the non-expressive way of infected persons about their health to the health workers/authorities for initial screening. Although, preventive measures such as social distancing, quarantine, and isolation methods were taken worldwide. These preventive measures were proved effective, when the appropriate pharmacological techniques and experiments did not cure so much [1, 27].

There is a large part of the world's population which could require more care and timely medical assistance for their livelihood and this age group of 'Elderly people (with age 50 years and greater)', could have more chances of infection due to COVID-19 and became the major part of total death cases of worldwide infected cases $[13,25]$. In India till 14/04/2020, the total death cases increased to 392, in which most of the death cases pointed to specific agegroup of elderly people [8]. According to census-2011, $15.92 \%$ of the total population belongs to the age group of 50 years and greater, and the effect of the present COVID19 outbreak needs to be studied concerning this age group

Table 1 Date wise confirmed cases/deaths and its percent increase

\begin{tabular}{lrc}
\hline Date of reporting & Confirmed cases & Number of deaths \\
\hline $14 / 04 / 2020$ & 11,488 & 392 \\
$11 / 04 / 2020$ & 8454 & 288 \\
$08 / 04 / 2020$ & 5095 & 166 \\
$04 / 04 / 2020$ & 2650 & 68 \\
$28 / 03 / 2020$ & 909 & 19 \\
$24 / 03 / 2020$ & 511 & 10 \\
$14 / 03 / 2020$ & 84 & 2 \\
$09 / 03 / 2020$ & 44 & 0 \\
$13 / 02 / 2020$ & 3 & 0 \\
$30 / 01 / 2020$ & 1 & 0 \\
\hline
\end{tabular}

$[4,17]$. The work in this paper presents the forecast of the total infection cases and possible death cases in this age group of 'Elderly people' in India. Several dynamic models were applied concerning the population of India to predict the number of infected elderly people and death cases of elderly people in the coming 21 days up to 05/05/2020. Further, the investigation was also deeply studied for some of the states/regions of India.

\section{Methods}

\section{Data}

The real-time updated data of the cumulative number of cases of confirmed, death, and cured in India and rest of the world was taken from COVID-19 Tracker India [8], Dong et al. [11] and Ritchie [22]. The database source recorded the daily update of the region/state/UT based number of confirmed/reported, death and cured cases up to 14/04/ 2020. The cumulative projections could be considered for estimating the predictions for the next 21 days, since the database might contain some irregularities and some reporting delays.

\section{Prediction Models}

Wang et al. [26] analyzed the outbreak of the Canada 2009 H1N1 outbreak, GTA 2003 SARS outbreak, Singapore 2005 dengue outbreak, and the Taiwan 2003 SARS outbreak using a constrained Richards model. Pell et al. [20] implemented a generalized Richards model to forecast the impact of epidemics such as EBOLA 2015 on the human population and predicted the final epidemic size. Chowell et al. [5] analyzed the outbreak of Severe Acute Respiratory Syndrome (SARS) in Singapore, plague in Madagascar, and also Ebola in the Democratic Republic of Congo (DRC). Pan et al. [19] analyzed the time duration of lung changes on chest CT during recovery from COVID-19 epidemic. Diao et al. [10] suggested that the cure rate could be used to analyze the treatment effectiveness in various medical techniques and could be significant for epidemic decision-making. Perc et al. [21] used the mathematical model to analyze the behavior of COVID-19 over various countries worldwide and also estimated the growth rate of COVID-19 for 21 days for different countries such as the USA, Slovenia, Iran, and Germany. Singh et al. [23] analyzed the impact of social distancing on the transmission of COVID-19 and predicted the duration of the lockdown period for India based on available data till 25/03/2020. But, after 25/03/2020, there was a dramatic increase in infectious COVID-19 cases due to a religious gathering, and transmission trends were terribly changed. In the 
present work, the autoregressive mathematical model was used to forecast the impact of COVID-19 for the next 21 days till 05/05/2020 in India and also the impact of the current outbreak on the most sensitive age group of 50 and greater in India. Further, the investigation was also performed for some of the states/regions of India.

\section{Mathematics of Model}

An Autoregressive Integrated Moving Average (ARIMA) model is a generalization of an Autoregressive Moving Average (ARMA) technique used for time series data analytics to better understand the data or to predict future forecasting. ARIMA models are generally applied in nonstationary data $[9,15,16,18]$. ARIMA model is presented as

ARIMA $(L, D, M)$

where $L, D, M$ are non-negative integers. In the ARIMA model, $L$ denotes time lags or the number of autoregressive terms, $D$ is the degree of differencing or the number of non-seasonal differences and $M$ reflects the order of the moving-average or number of lagged forecast errors in the prediction equation.

The ARIMA forecasting equation $\left(f_{t}^{\prime}\right)$ is constructed as follows.

$f_{t}^{\prime}=\mu+\phi_{1} f_{t-1}+\phi_{1} f_{t-2}+\ldots+\phi_{t} f_{t}$

where $\mu$ denotes mean, $\phi$ is moving average parameters, and $f$ denotes $k$ th difference of $F$, such as

$$
\begin{aligned}
& \text { If } k=0: f_{t}=F_{t} \\
& \text { If } k=1: f_{t}=F_{t}-F_{t-1} \\
& \text { If } k=2: f_{t}=\left(F_{t}-F_{t-1}\right)-\left(F_{t-1}-F_{t-2}\right)=F_{t}-2 F_{t-1}+F_{t-2}
\end{aligned}
$$

\section{Results and Discussion}

The investigation was divided into four cases: Case I presented the total number of COVID-19 infectious, death, cured cases, and impact on the population of India till $14 / 04 / 2020$ and projected the results for the next 21 days till 05/05/2020. Case II presented the impact of the outbreak on the different states/regions of India and predicted the transmission in the next 21 days. Case III presented the impact of COVID-19 on the most sensitive age group in India. Case IV summarized the available facts regarding COVID-19 and epidemic transmission.

\section{Case I (A): Trends and Prediction of COVID-19 for Globe and India}

The present and predicted trends for the coming 21 days for the global situation and especially India were highlighted in this section. The global and Indian trends for infectious, death, and recovered cases are presented in Figs. 1 and 2, respectively.

\section{Case I (B): Impact of COVID-19 on Population of India as Per Census 2011 and Projected 2019}

In this section, the impact of the COVID-19 outbreak was considered over the population of India. To consider the impact over the population of India, the population considerations were done according to Census-2011 [4] and the projected population for 2019 [24]. According to the Census-2011, the total population of India was $1,210,854,977$, which was projected to be $1,353,890,423$ in 2019 as per available resources. The projected impact over the population according to census-2011 and projected 2019 is presented in Figs. 3 and 4.

\section{Discussion}

The horrifying trends of the COVID-19 pandemic predicted more than 115,000 deaths in just 101 days in the worldwide scenario. The worldwide actual and predicted number of infected and death cases till 14/04/2020 and for the coming 21 days till 05/05/2020 are presented in Fig. 1. It was observed from the results that if the outbreak of this infectious virus could not be controlled timely then the estimated 3,500,000 of infected cases would be found around the globe as presented in Fig. 1a and the graph of the death cases would also rise to the peak and the approximate number of deaths become 250,000 as presented in Fig. $1 b$.

India is the second-ranked country in terms of population and also not much affected by COVID-19 outbreak yet. With the decision of early lockdown, this outbreak was supposed to be controlled. But, it could become mandatory to estimate the transmission of this dangerous virus in coming days, thus the statistical predictions for India are presented in Fig. 2 and it was predicted for next 21 days till 05/05/2020 that more than 35,000 persons would be affected with this deadly virus in pre-implemented controlled conditions such as lockdown, social distancing, etc. throughout the whole country as presented in Fig. 2a. It was also observed from Fig. $2 b$ that the death cases would also be raised to more than 1400 in the coming 21 days. The human immunity plays a vital role in fighting COVID19 infection and in the light this fact, till now around 1000 
infected persons were recovered and this number will become more than 7000 in the coming 21 days as presented in Fig. 2c.

The present pandemic outbreak could affect the large portion of the population of India and this impact is presented in Figs. 3 and 4. Since the last census was done in 2011 and actual data was available regarding population, then it was observed from Fig. 3a that, $0.003130 \%$ of the population could be infected by COVID-19 virus and $0.000116 \%$ portion of the population could be dead in next 21 days prediction as presented in Fig. 3b. A similar prediction could be done over the increased and projected population of 2019 in India and observations from Fig. 4a, b could be depicted that population percentage of 0.002789 could become infectious and death cases could become $0.000104 \%$ of the projected population-2019, respectively.
Fig. 2 India trends and predictions of COVID-19

The recovery rate seemed to be much less than the infection rate, but cured/recovered cases could become the important factor to lower down the horrifying fear of outbreak and $0.000535 \%$ and $0.000478 \%$ of the total population of India as per census-2011 and projected 2019 could be recovered from this deadly virus infection till 05/05/ 2020 as presented in Figs. 3 and 4, respectively.

\section{Case II: Trends and Prediction of COVID-19 in States/Regions of India}

The nation wise COVID-19 virus impact was considered in Case I but it could be important, to study the virus transmission through state/region wise scenario. This section

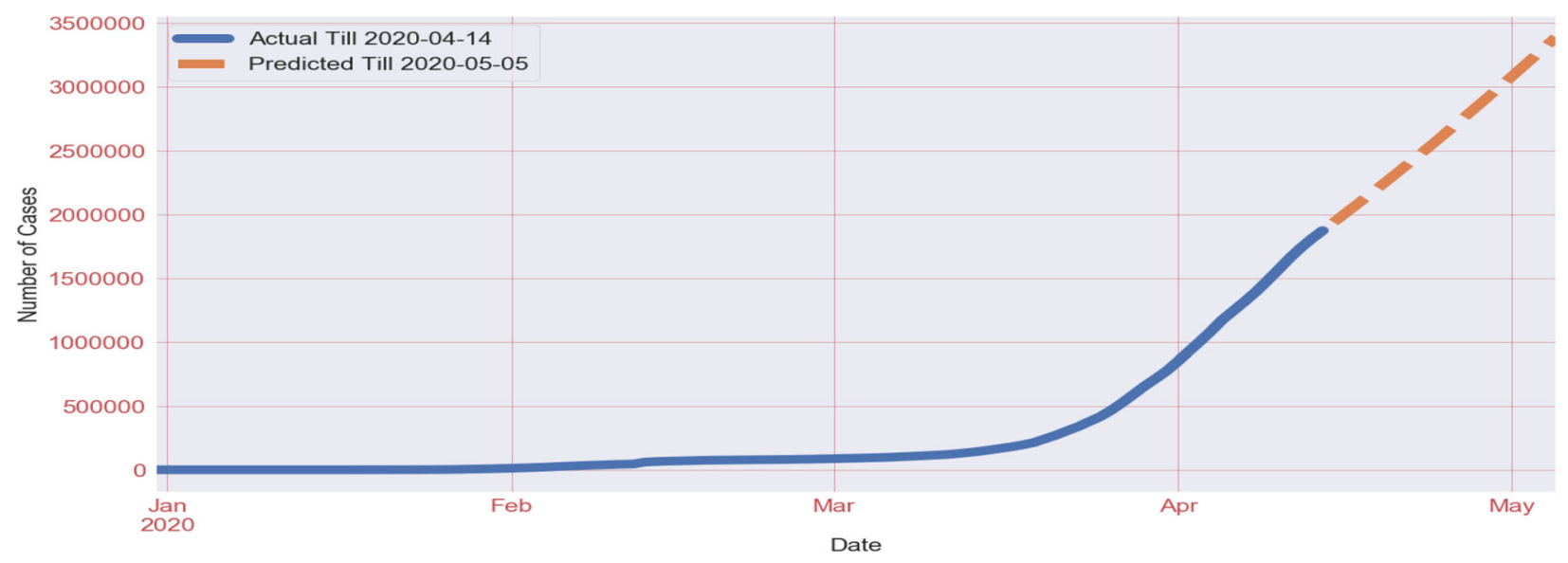

(a) Worldwide Projected Infectious Cases

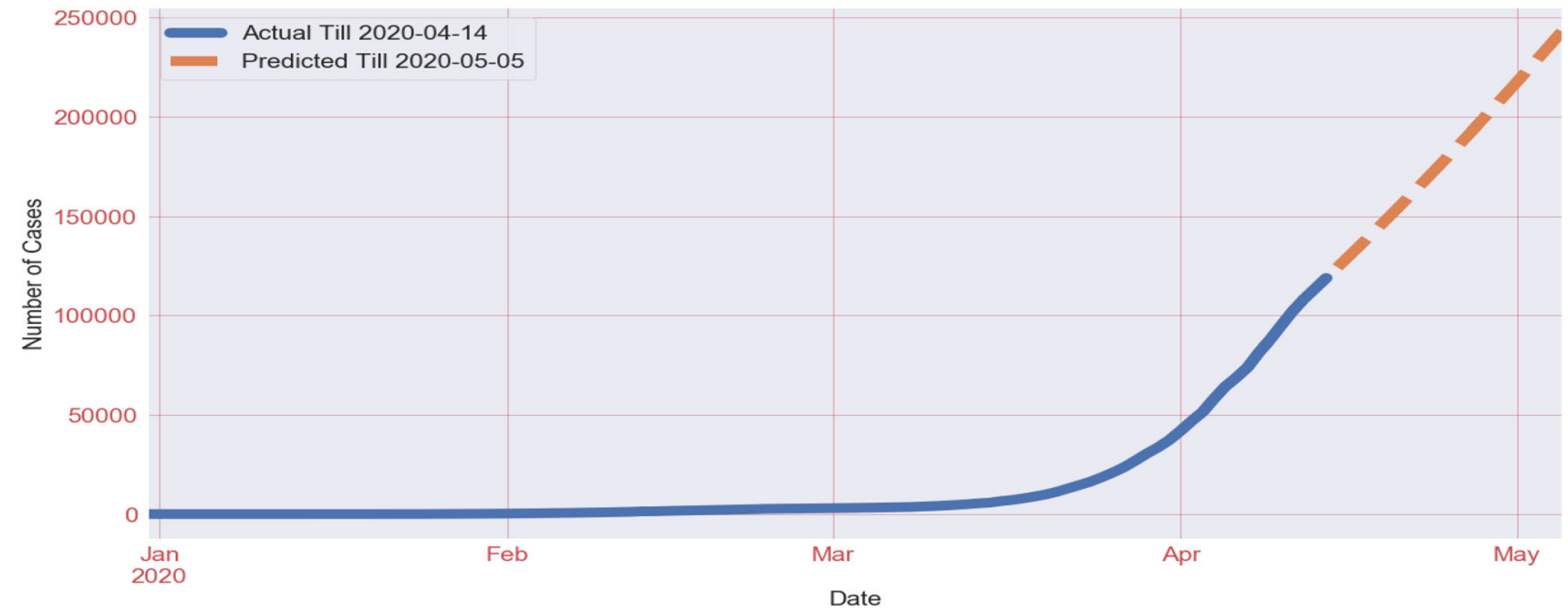

(b) Worldwide Projected Death Cases

Fig. 1 World trends and predictions of COVID-19 


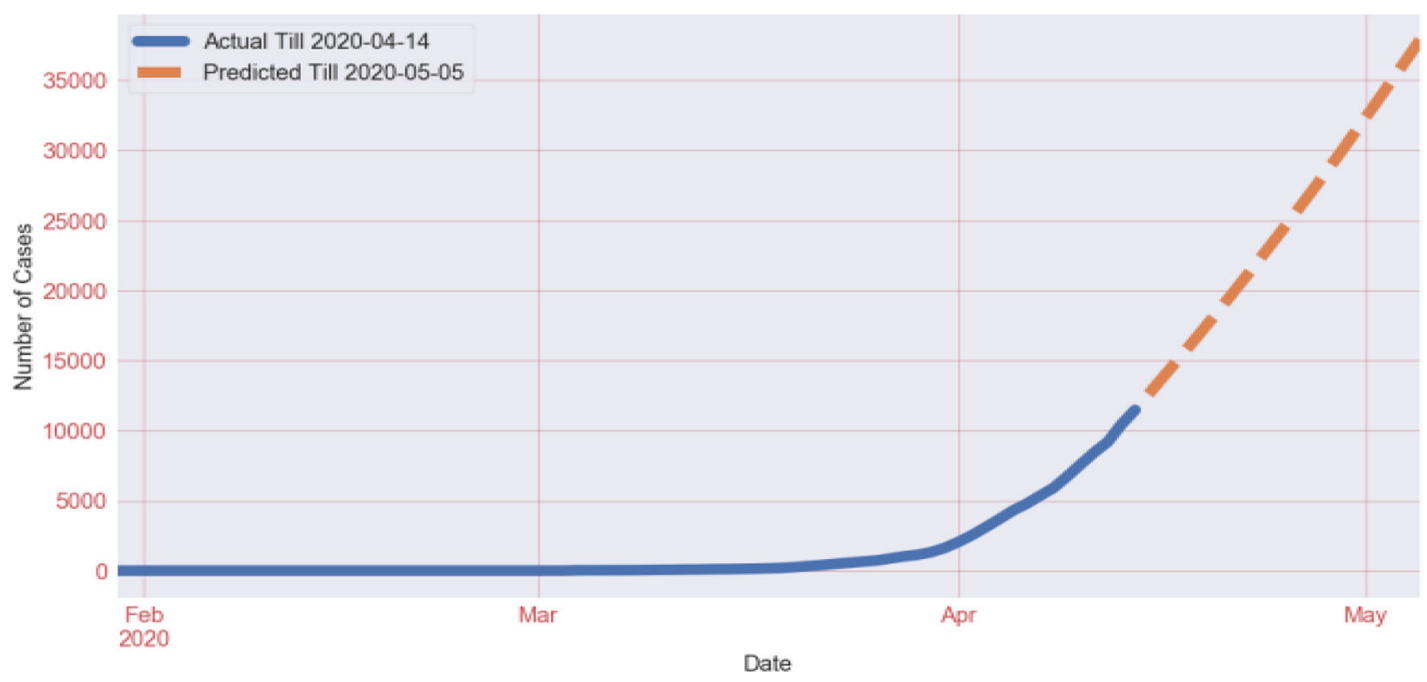

(a) Prediction for Infected Cases till 05/05/2020

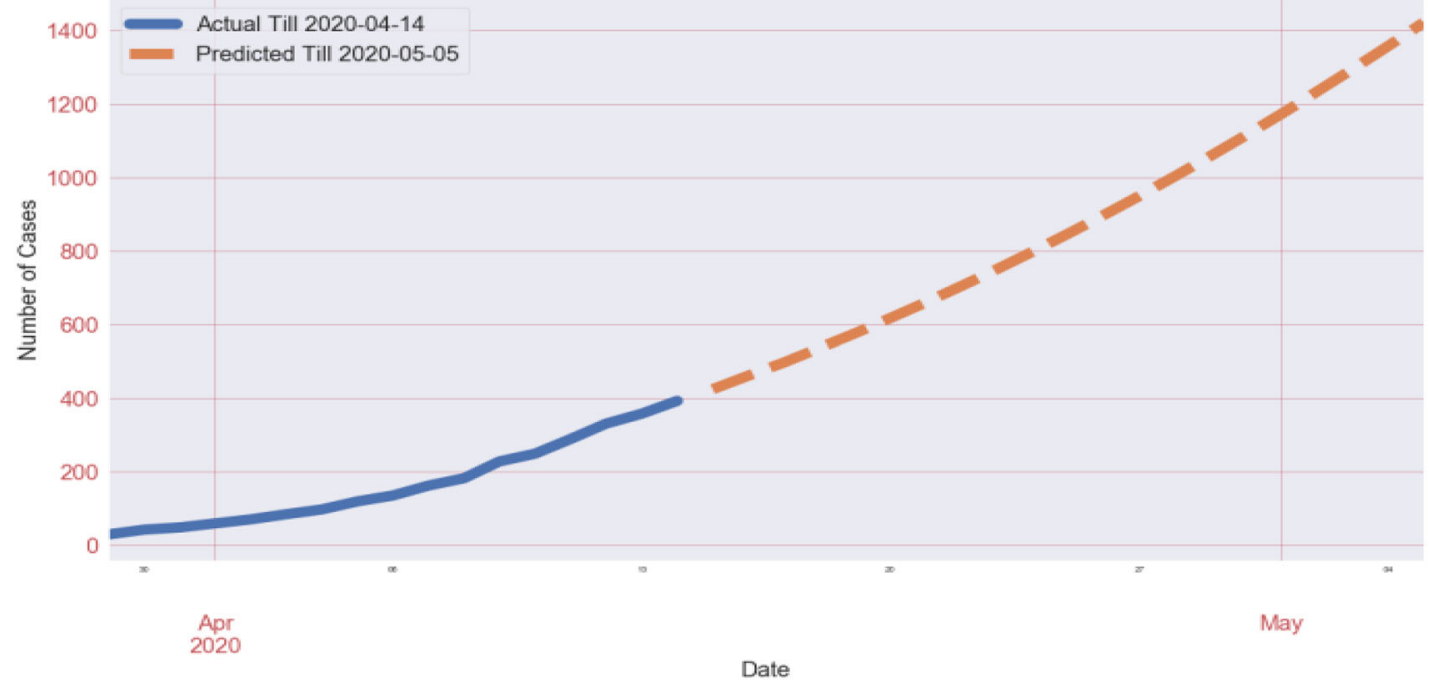

(b) Prediction for Death Cases till 05/05/2020

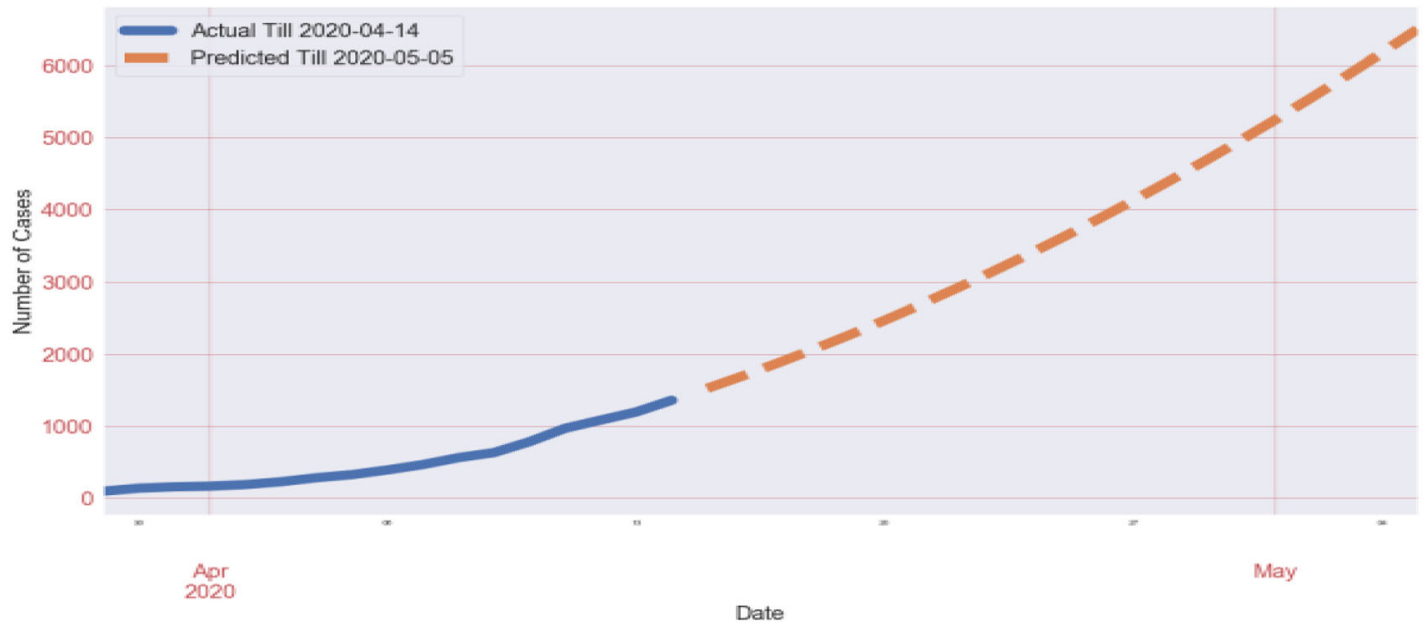

(c) Prediction for Cured/Recovered Cases till 05/05/2020 
presented the trends and prediction of virus impact over various states and regions of the Republic of India. The comparison of state/region wise impact according to Census-2011 and Projected-2019 population is presented in Fig. 5. Further, the state/region wise projected infectious, death and cured cases are presented in Fig. 6.

\section{Discussion}

It was observed from the results presented in Figs. 5 and 6 that impact of the current virus outbreak could be crucial and the predicted high-risk state/regions could be Delhi, Maharashtra, Tamilnadu, Kerala, Gujrat, Rajasthan, Telangana, Andhra Pradesh, Madhya Pradesh, Goa, and Punjab. The prediction peaks for infection cases for the next 21 days (for both census-2011 and projected-2019 population) were very high in the highlighted states as presented in Fig. 5. The most infectious states/regions such as Maharashtra (infectious cases $>2650$ ), Delhi (infectious cases $>1550$ ), Tamilnadu (approximately 1200 infectious cases) etc. had put the population at high risk. In some regions, the rate of virus infection became double or more in a few days such as Punjab. It was also observed from Fig. 6 that the predictions for death cases could also be high in the coming 21 days. The major portion of the state/ region could be infectious in the next 21 days if the virus outbreak continues as per its current transmission rate. The precautionary measures need to be imposed in the high infected areas and spreading hotspot areas should also be identified in all states/regions as soon as possible. The state/region wise projected trends for infection cases in the next 21 days from data recorded date (14/04/2020) are presented in Fig. 6.

\section{Case III: Impact of COVID-19 on High-Risk Elderly People in India}

The analysis in Case I and Case II presented the population-wise impact of present outbreak India and various states/regions in India. But the impact of the current pandemic and its transmission should also be considered agewise, and it was predicted that the elderly group of the population could be at high risk. The death rate trends and prediction as per the Indian scenario are presented in Fig. 7.

\section{Discussion}

The death impact of COVID-19 over the different agegroups was considered for the worldwide infectious case as presented in Fig. 7a. It was observed from the global scenario that the age group of the elderly population (50 years and greater) could be at high risk of death in comparison to other defined age groups as presented in Fig. 7a. In context with the Indian scenario, the total population (Census2011) was divided in similar age-group and it was found that $15.92 \%$ persons belong to the age group of elderly people (with age 50 years and greater), $25.58 \%$ and $58.5 \%$ related to the age group of 30-49 years and 0-29 years, respectively, as presented in Fig. 7b. The forecast mathematical model was also applied to the population of India for age-wise prediction and the results of the possible prediction are presented in Fig. 7b. It was observed from Fig. $7 \mathrm{c}$ that the death cases belonging to the age group of 50 years and greater could rise to near 400 in the next 21 days.

\section{High-Risk Population}

Since the elderly age group could be at a very high risk of infection due to COVID-19, and then it could become mandatory to discuss the total high-risk population of India. As per publication by the Ministry of Statistics and Programme Implementation of India regarding elderly in India [12], 8.6\% population (104,133,528 people) belonged to elderly people were present in Census-2011 and this was projected to be around $10 \%(135,389,042$ people) in the projected population of 2019 [2]. The large portion of the population could be more prone to COVID-19 virus infection and death. The state-wise \% of the elderly population and the predicted high-risk population are presented in Table 2. If the contribution of this age group in economic section of the country is considered, then it was found that $41.6 \%$ of this age-group people are responsible for strengthening the economic ground of India and as per census-2011, the total population became 503,715,670 persons, which is at high risk in current pandemic. If the same economic percentage could be applied to the projected population of India in 2019, then the population number could be increased to $563,218,416$ persons. If the social distancing and lockdown could not be followed then this population portion could be at very high risk. As per published ICMR study that the R0 value for the current coronavirus infection was considered to be 2.5 and if the social exposure reduced by $75 \%$, then one sick person can only infect 2.5 persons in 1 month [14]. But, in case, the social distancing and proper lockdown conditions are not properly followed by the citizens of India, then the scenario will be different and terrible.

The present study will be in favor of proper lockdown for the next 21 days and further extension if needed and also the strict norms of social distancing should be followed. In the presence of limited resources, proper health care of high-risk age-group should be taken to stop the spread of COVID-19 and also to control the causality to high-risk age group. 
Fig. 3 Projected impact of COVID-19 on population of India (census-2011)

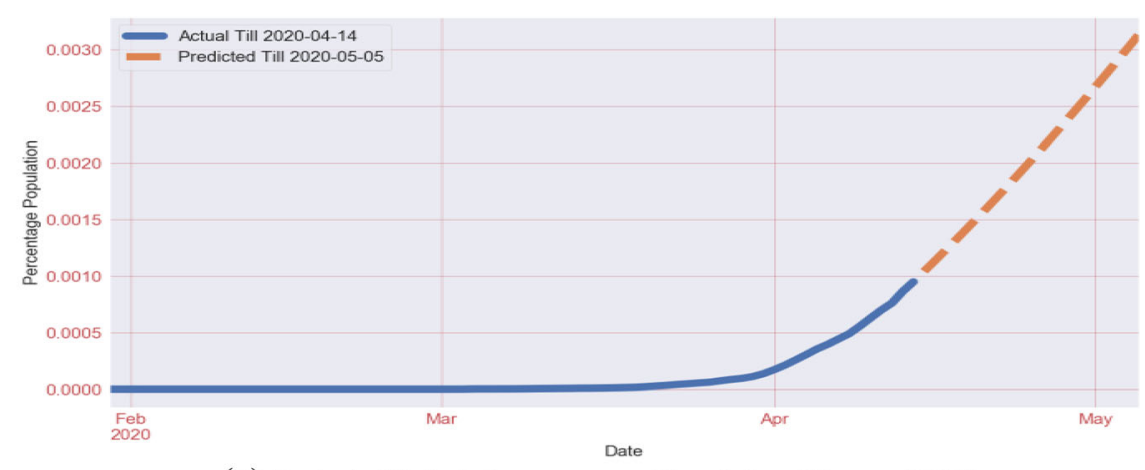

(a) Projected Infected cases as per Population (Census-2011)

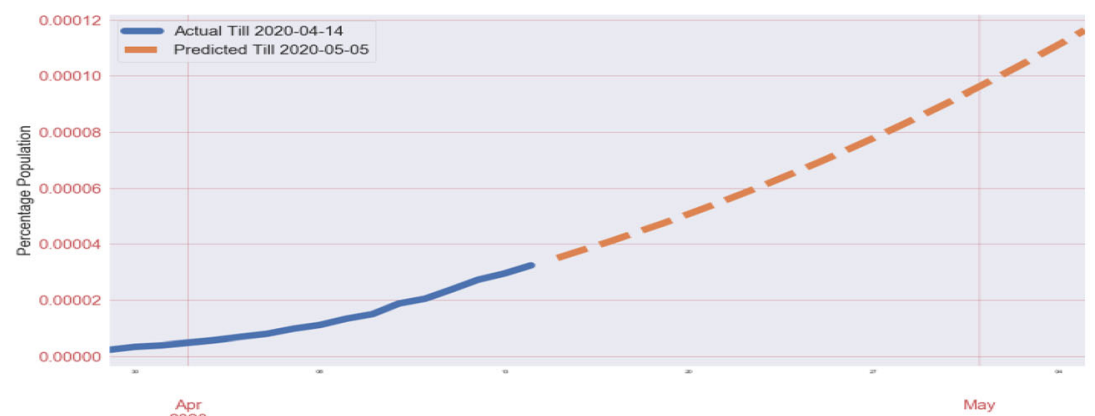

(b) Projected Death cases as per Population (Census-2011)

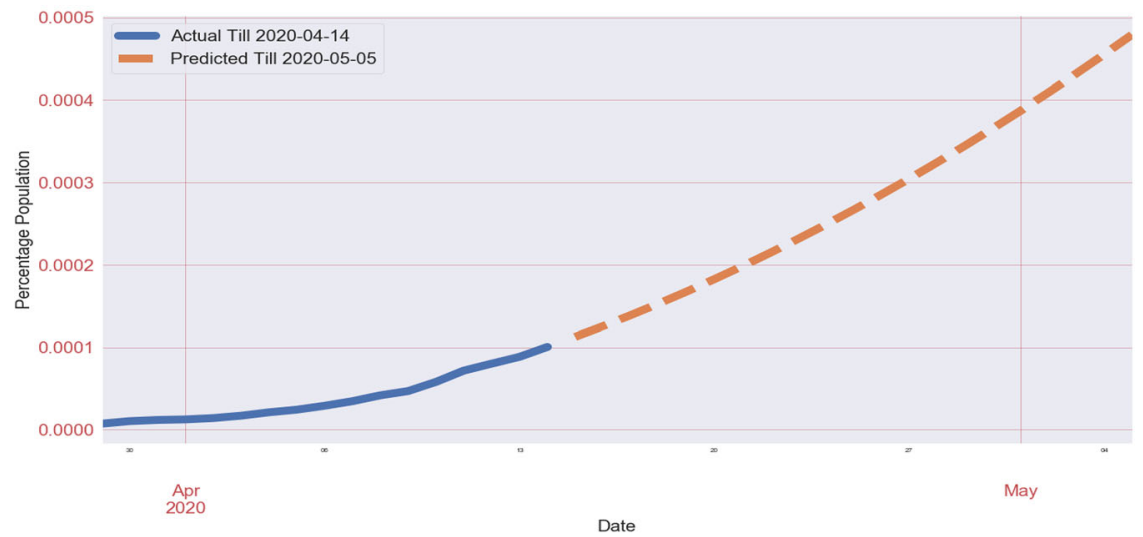

(c) Projected Cured/Recovered as per Population (Census-2011)

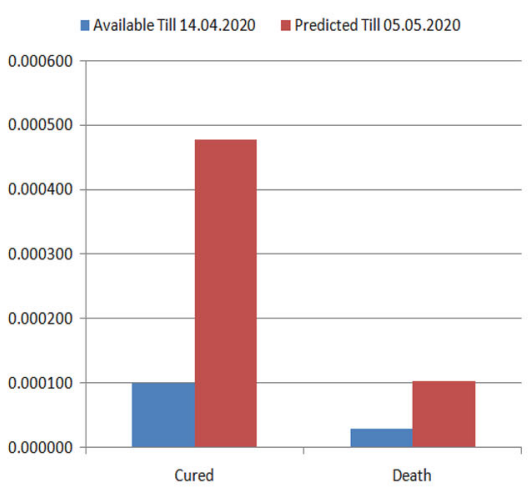

(d) Comparison Cured versus Death Percentage (Census -2011)

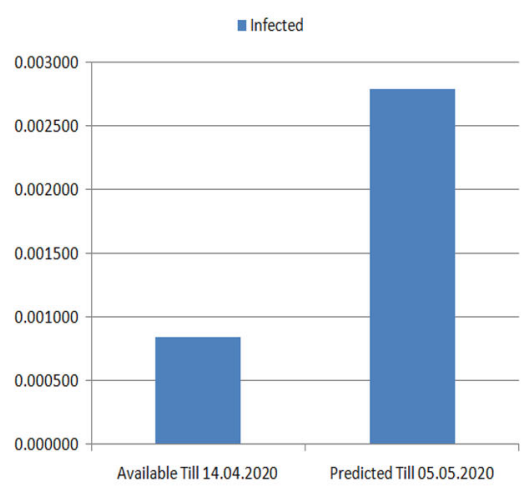

(e) Infected Cases Percentage (Census 2011) 
Fig. 4 Projected impact of COVID-19 on population of India (projected population2019)

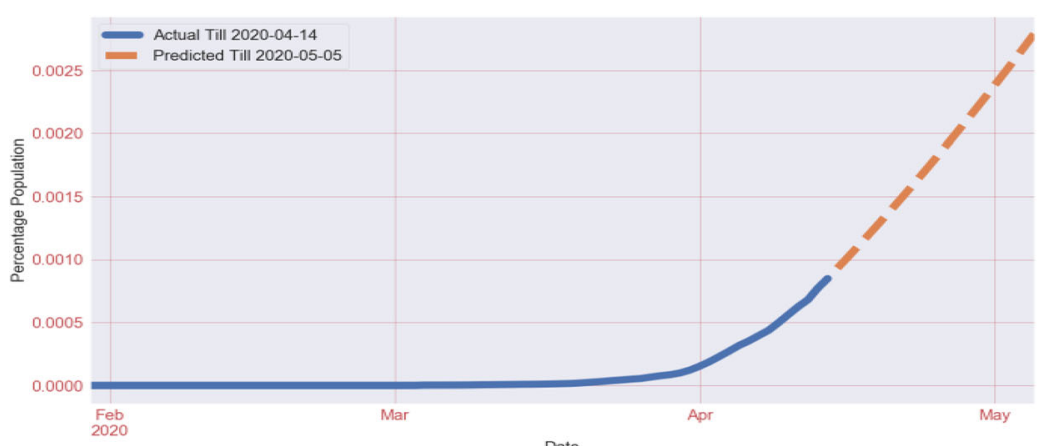

(a) Projected Infected Cases as per Projected Population in 2019

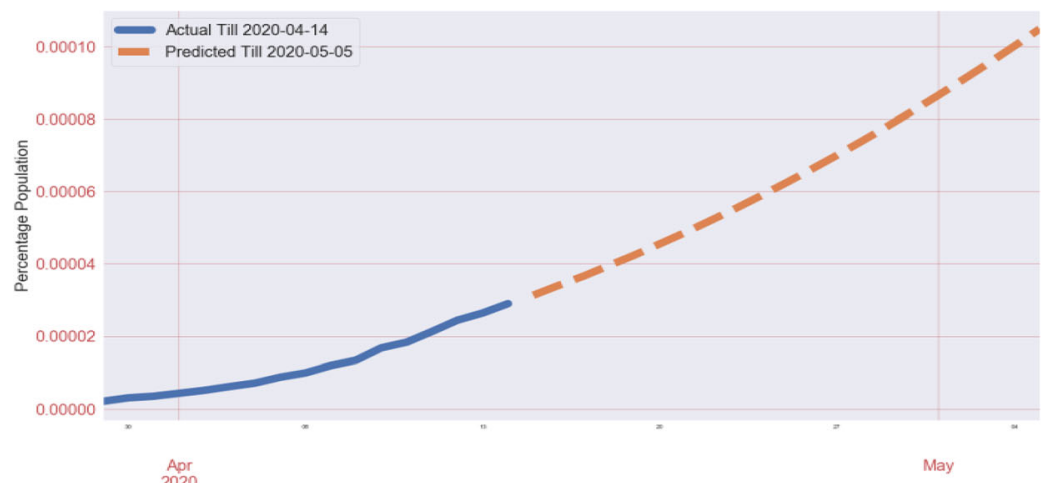

Date

(b) Projected Death Infected Cases as per Projected Population in 2019

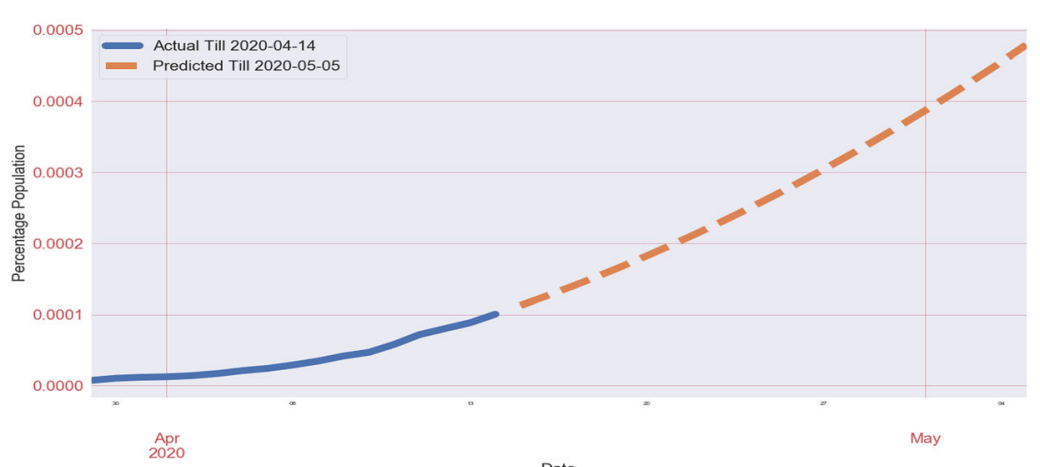

(c) Projected Cured/Recovered Infected Cases as per Projected Population in 2019

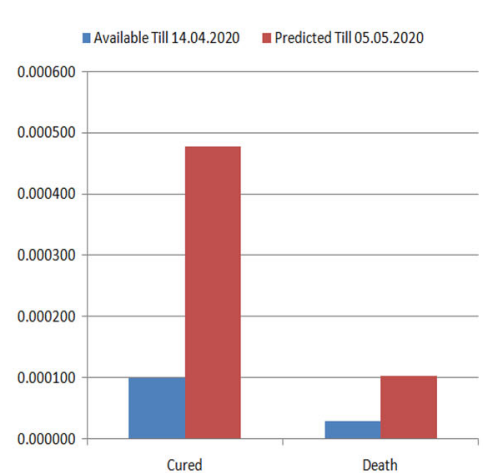

(d) Comparison Cured versus Death Percentage as per Projected Population in 2019

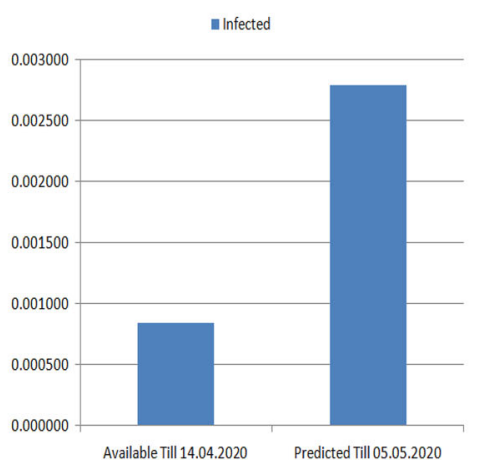

(e) Infected Cases Percentage as per Projected Population in 2019 
Fig. 5 Comparison of trends and prediction of COVID-19 in states/regions of India available Till 14.04.2020 $\square$ Predicted Till 05.05.2020

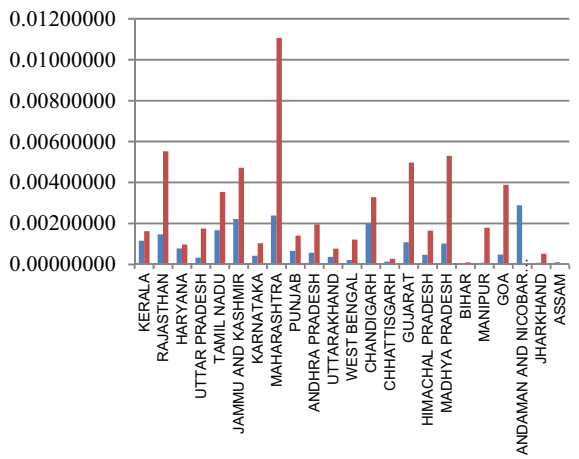

(a) Comparison Infected Percentage as per Census-2011

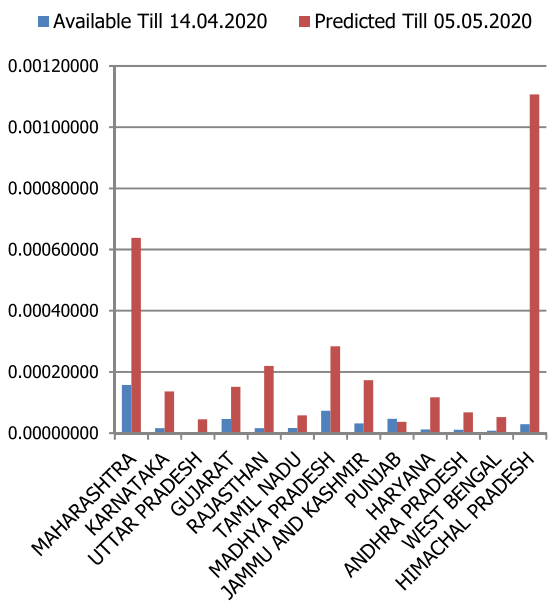

(c) Comparison Death Percentage as per Census-2011

available Till 14.04.2020 a Predicted Till 05.05.2020

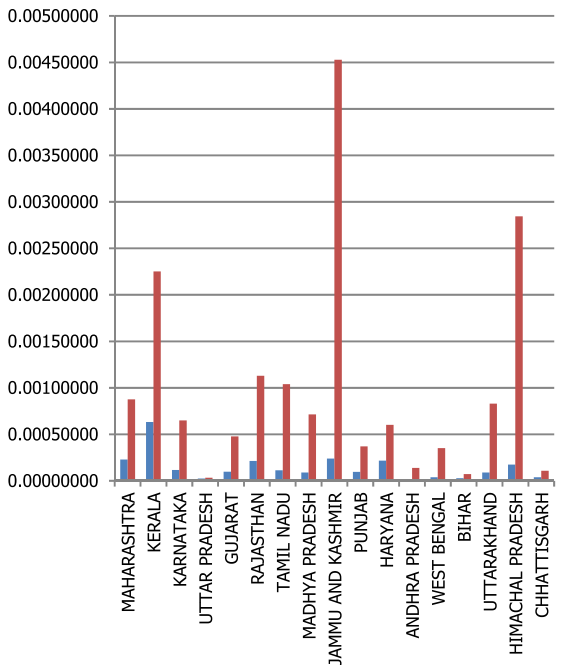

(e) Comparison Cured Percentage as per Census-2011
— Available Till 14.04.2020 $\approx$ Predicted Till 05.05.2020

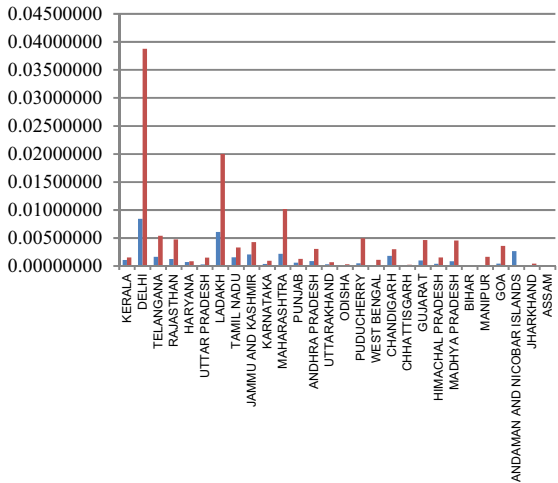

(b) Comparison Infected Percentage as per Projected Population in 2019

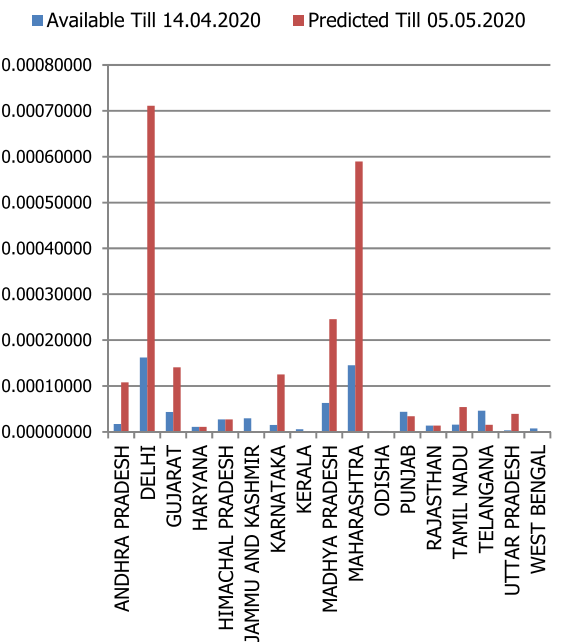

(d) Comparison Death Percentage as per Projected Population in 2019

n Available Till 14.04.2020 — Predicted Till 05.05.2020

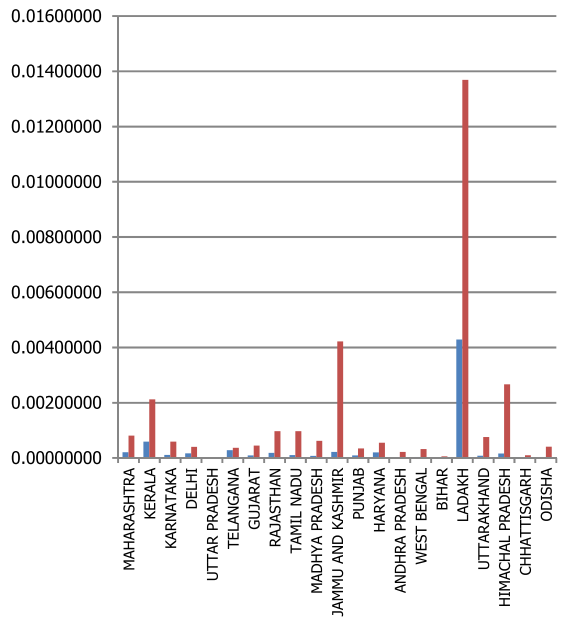

(f) Comparison Cured Percentage as per Projected Population in 2019 


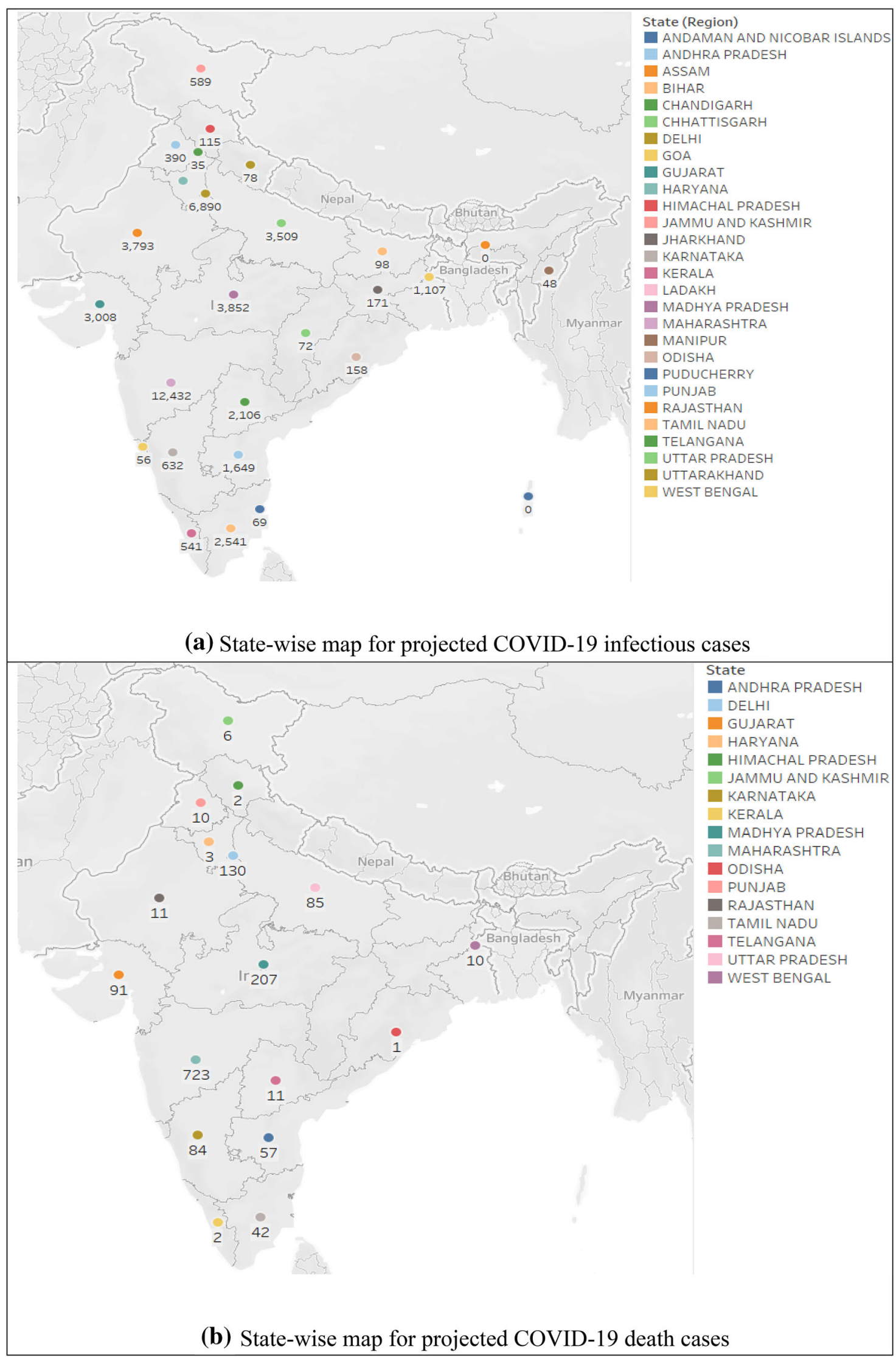


4Fig. 6 States/region wise prediction of COVID-19 in India till 05/05/ 2020

\section{Conclusions}

The frightening effects of the current outbreak of COVID19 can be observed all over the globe, and several medical/social efforts are in progress to stop/control the transmission of the 2019-nCoV virus. It was necessary to study the impact of current pandemic over the different age-group population in various countries with satisfactory or limited health resources since the virus outbreak affected almost all countries in the world irrespective of development in the medical sector. The work in the present study analyzed the trends of noble coronavirus outbreak globally and also deep analysis was performed over the population of the Republic of India. The analysis and predictions were

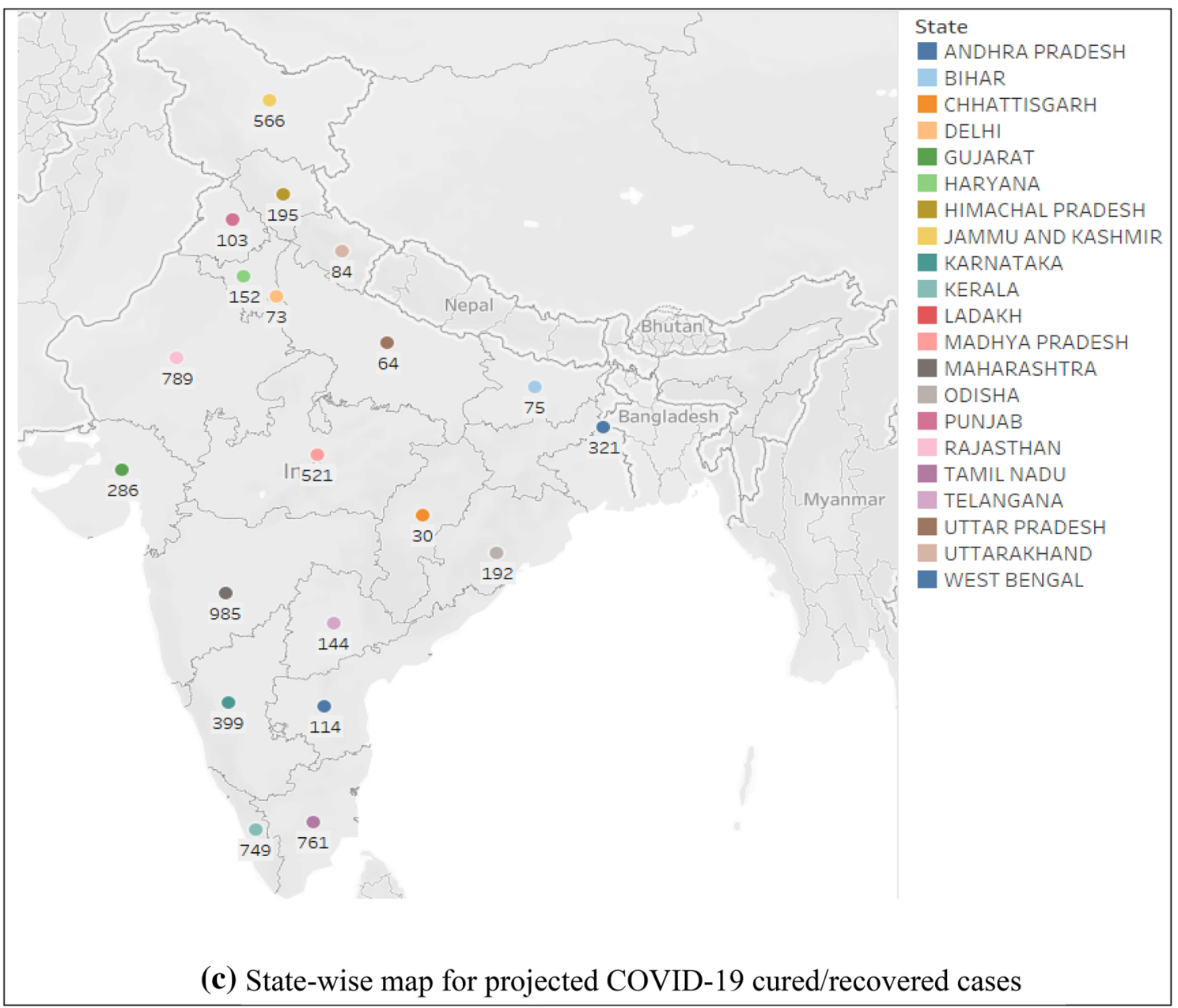

Fig. 6 continued 
Fig. 7 Impact analysis of COVID-19 on age group (50 years and greater) in India

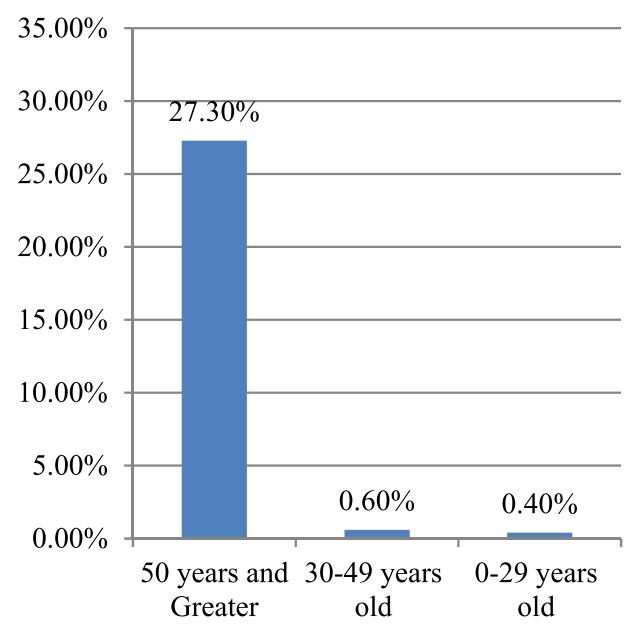

(a) Worldwide age-wise Death Rate trends

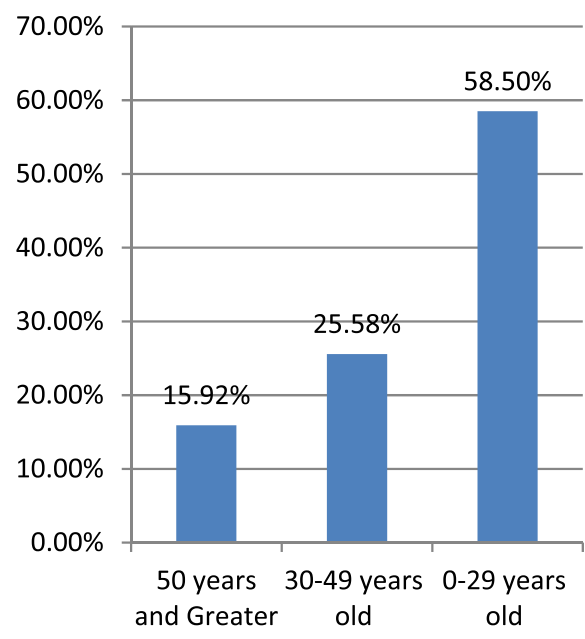

(b) Population Distribution in India (Census-2011)

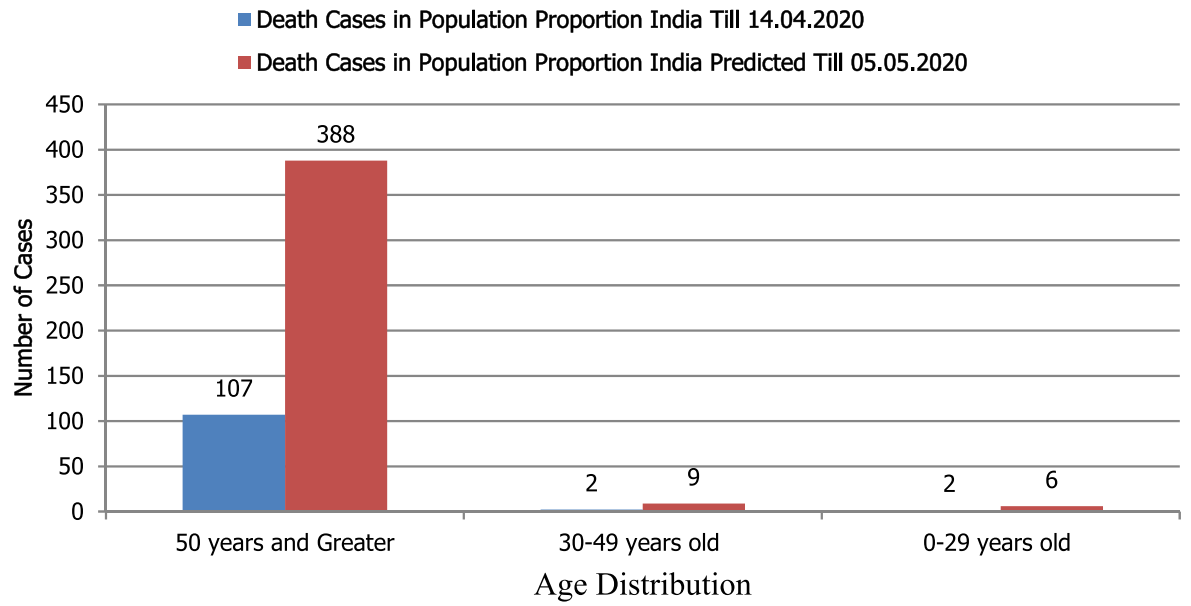

(c) Age-wise Death Prediction in India 
Table 2 Analysis of high risk elderly population

\begin{tabular}{|c|c|c|c|c|c|}
\hline State/UT/region & $\begin{array}{l}\% \text { elderly } \\
\text { population }\end{array}$ & $\begin{array}{l}\text { Elderly population } \\
\text { (person) }\end{array}$ & $\begin{array}{l}\text { State/UT/ } \\
\text { region }\end{array}$ & $\begin{array}{l}\% \text { elderly } \\
\text { population }\end{array}$ & $\begin{array}{l}\text { Elderly population } \\
\text { (person) }\end{array}$ \\
\hline \multicolumn{6}{|c|}{ High risk COVID-19 (Census-2011) } \\
\hline Andhra Pradesh & 9.8 & $8,288,916$ & Lakshadweep & 8.2 & 5287 \\
\hline $\mathrm{A}$ and $\mathrm{N}$ Islands & 6.7 & 25,499 & $\begin{array}{l}\text { Madhya } \\
\text { Pradesh }\end{array}$ & 7.9 & $5,737,518$ \\
\hline Arunachal Pradesh & 4.6 & 63,651 & Maharashtra & 9.9 & $11,125,059$ \\
\hline Assam & 6.7 & $2,090,774$ & Manipur & 7 & 199,906 \\
\hline Bihar & 7.4 & $7,703,359$ & Meghalaya & 4.7 & 139,444 \\
\hline Chandigarh & 6.4 & 67,549 & Mizoram & 6.3 & 69,124 \\
\hline Chhattisgarh & 7.8 & $1,992,525$ & Nagaland & 5.2 & 102,882 \\
\hline $\begin{array}{l}\text { Dadra and Nagar } \\
\text { Haveli }\end{array}$ & 4 & 13,748 & Odisha & 9.5 & $3,987,551$ \\
\hline Daman and Diu & 4.7 & 11,433 & Puducherry & 9.7 & 121,051 \\
\hline Delhi & 6.8 & $1,141,580$ & Punjab & 10.3 & $2,857,564$ \\
\hline Goa & 11.2 & 163,357 & Rajasthan & 7.5 & $5,141,133$ \\
\hline Gujarat & 7.9 & $4,774,736$ & Sikkim & 6.7 & 40,909 \\
\hline Haryana & 8.7 & $2,205,577$ & Tamil Nadu & 10.4 & $7,503,291$ \\
\hline Himachal Pradesh & 10.2 & 700,189 & Tripura & 7.9 & 290,239 \\
\hline Jammu and Kashmir & 7.4 & 928,056 & Uttar Pradesh & 7.7 & $15,385,550$ \\
\hline Jharkhand & 7.1 & $2,342,158$ & Uttarakhand & 8.9 & 897,680 \\
\hline Karnataka & 7.7 & $4,704,338$ & West Bengal & 8.5 & $7,758,470$ \\
\hline Kerala & 12.6 & $4,209,164$ & & & \\
\hline
\end{tabular}

performed for the next 21 days till 05/05/2020 and observed that the number of infectious and death cases could rise to the maximum number in the coming 21 days. The study also identified various high-risk Indian states/ regions which could become spreading hotspots in the country. Further, the impact of the outbreak was considered age-wise and it was found that the large percentage of the population, belong to the age group of elderly people (with age 50 years and greater), could be at a very high fatality risk and virus infection. The proper care must be taken and all necessary medical facilities should be provided to this age-group of elderly people so that the social distancing could be sacrificed.

The Government of the Republic of India had already taken very bold steps to control virus transmission such as a countrywide lockdown. The study is in favor of extending lockdown up to the next 21 days or more if needed to slow down the virus spread throughout the country and the norms of social distancing should be strictly implemented to avoid any region or person becoming super spreader and to stop community transmission. Random and mass testing will be proved effective to control or locate virus transmission. Further, larger areas should be divided into smaller zones and colony-wise and the mass level initial screening should be performed zones to identify the patients with initial symptoms. After the end of lockdown, when the normal routine would be resumed, still, then the proper sanitization and centralized initial screening mechanism with high-quality equipments should be implemented throughout the country to track the infected patients at various gathering areas such as restaurants/hotels, grocery stores, interstate transfer terminals, railway stations, toll checkpoints, airports, border entry/exit terminals, educational sectors, industries sectors, etc.

\section{Compliance with Ethical Standards}

Conflict of interest We (Authors) have no conflict of interest regarding manuscript entitled "Estimating the Impact of Covid-19 Outbreak on High-Risk Age Group Population in India".

\section{References}

1. Adhikari SP, Meng S, Wu YJ, Mao YP, Ye RX, Wang QZ, Sun C, Sylvia S, Rozelle S, Raat H, Zhou H (2020) Epidemiology, causes, clinical manifestation and diagnosis, prevention and control of coronavirus disease (COVID-19) during the early outbreak period: a scoping review. Infect Dis Poverty 9(1):1-12. https://doi.org/10.1186/s40249-020-00646-x 
2. Agarwal A, Lubet A, Mitgang E, Mohanty S, Bloom DE (2020) Population aging in india: facts, issues, and options, issue 10162, pp 289-311. https://doi.org/10.1007/978-981-10-0230-4_13

3. Anzai A, Kobayashi T, Linton NM, Kinoshita R, Hayashi K, Suzuki A, Yang Y, Jung S, Miyama T, Akhmetzhanov AR, Nishiura H (2020) Assessing the impact of reduced travel on exportation dynamics of novel coronavirus infection (COVID19). J Clin Med 9(2):601. https://doi.org/10.3390/jcm9020601

4. Census-India (2011) https://censusindia.gov.in/2011-Common/ CensusData2011.html. Accessed 15 Apr 2020

5. Chowell G, Tariq A, Hyman JM (2019) A novel sub-epidemic modeling framework for short-term forecasting epidemic waves. BMC Med 17(1):1-18. https://doi.org/10.1186/s12916-019-14066

6. Coronavirus Disease (COVID-2019) Situation Reports (2020) World Health Organization. https://www.who.int/emergencies/ diseases/novel-coronavirus-2019/situation-reports/. Accessed 15 Apr 2020

7. Coronavirus Disease 2019 (COVID-19) Situation Report-66 (2020) World Health Organization. https://www.who.int/docs/ default-source/coronaviruse/situation-reports/20200326-sitrep66-covid-19.pdf?sfvrsn=9e5b8b48_2. Accessed 15 Apr 2020

8. COVID-19 Tracker India (2020) https://www.covid19india.org/. Accessed 15 Apr 2020

9. Dehesh T, Mardani-Fard HA, Dehesh P (2020) Forecasting of COVID-19 confirmed cases in different countries with ARIMA models. MedRxiv. https://doi.org/10.1101/2020.03.13.20035345

10. Diao Y, Liu X, Wang T, Zeng X, Dong C, Zhang Y, Zhou C, She $X$, Liu D, Hu Z (2020) Estimating the cure rate and case fatality rate of the ongoing epidemic COVID-19. MedRxiv 10(2):1-8. https://doi.org/10.1101/2020.02.18.20024513

11. Dong E, Du H, Gardner L (2020) An interactive web-based dashboard to track COVID-19 in real time. Lancet Infect Dis 3099(20):19-20. https://doi.org/10.1016/S1473-3099(20)30120-1

12. Elderly In India (2016) Situation analysis of elderly persons in India. www.mospi.gov.in. Accessed 15 Apr 2020

13. Fischer F, Raiber L, Boscher C, Winter MH (2020) COVID-19 and the elderly: who cares? Front Public Health. https://doi.org/ 10.3389/fpubh.2020.00151

14. ICMR Study (2020) https://economictimes.indiatimes.com/news/ politics-and-nation/icmr-study-suggests-1-covid-patient-caninfect-406-people-in-30-days-in-absence-of-self-isolation-govt/ articleshow/75028122.cms. Accessed 15 Apr 2020

15. Kumar P, Kalita H, Patairiya S, Sharma YD, Nanda C, Rani M, Rahmani J, Bhagavathula AS (2020) Forecasting the dynamics of COVID-19 pandemic in top 15 countries in April 2020: ARIMA model with machine learning approach. MedRxiv. https://doi.org/ $10.1101 / 2020.03 .30 .20046227$
16. Kumar P, Singh RK, Nanda C, Kalita H, Patairiya S, Sharma YD, Rani M, Bhagavathula AS (2020) Forecasting COVID-19 impact in India using pandemic waves Nonlinear Growth Models. MedRxiv. https://doi.org/10.1101/2020.03.30.20047803

17. Mishra VK (2019) India's projected aged population (65+), projected life expectancy at birth and insecurities faced by aged population. Ageing Int. https://doi.org/10.1007/s12126-01909350-0

18. Moftakhar L, Seif M (2020) IRANIAN the exponentially increasing rate of patients infected with COVID-19 in Iran. Acad Med Sci IR Iran 23(4):235-238. https://doi.org/10.34172/aim. 2020.03

19. Pan F, Ye T, Sun P, Gui S, Liang B, Li L, Zheng D, Wang J, Hesketh RL, Yang L, Zheng C (2020) Time course of lung changes on chest CT during recovery from 2019 novel coronavirus (COVID-19) pneumonia. Radiology 78(4):200370. https:// doi.org/10.1148/radiol.2020200370

20. Pell B, Kuang Y, Viboud C, Chowell G (2018) Using phenomenological models for forecasting the 2015 Ebola challenge. Epidemics 22:62-70. https://doi.org/10.1016/j.epidem.2016.11. 002

21. Perc M, Gorišek Miksić N, Slavinec M, Stožer A (2020) Forecasting COVID-19. Front Phys 8:127. https://doi.org/10.3389/ fphy. 2020.00127

22. Ritchie H (2020) Coronavirus source data. https://ourworldindata. org/coronavirus-source-data. Accessed 15 Apr 2020

23. Singh R, Adhikari R (2020) Age-structured impact of social distancing on the COVID-19 epidemic in India. Quant Biol (Popul Eval) 1-9. https://arxiv.org/abs/2003.12055

24. State/UT wise Adhaar Saturation (2020) https://uidai.gov.in/ima ges/state-wise-aadhaar-saturation.pdf. Accessed 15 Apr 2020

25. Vahia IV, Blazer DG, Smith GS, Karp JF, Steffens DC, Forester BP, Tampi R, Agronin M, Jeste DV, Reynolds CF (2020) COVID-19, mental health and aging: a need for new knowledge to bridge science and service. Am J Geriatr Psychiatry. https:// doi.org/10.1016/j.jagp.2020.03.007

26. Wang XS, Wu J, Yang Y (2012) Richards model revisited: validation by and application to infection dynamics. $\mathrm{J}$ Theor Biol 313:12-19. https://doi.org/10.1016/j.jtbi.2012.07.024

27. Wu D, Wu T, Liu Q, Yang Z (2020) The SARS-CoV-2 outbreak: what we know. Int J Infect Dis. https://doi.org/10.1016/j.ijid. 2020.03.004

Publisher's Note Springer Nature remains neutral with regard to jurisdictional claims in published maps and institutional affiliations. 